\title{
Excessive participation in on-line internet action games by two American teenagers: Case report, description of extent of overuse, and adverse consequences
}

\author{
Richard H. Schwartz \\ Inova Children's Hospital, Falls Church, USA \\ Email: rhs738@aol.com \\ Received 1 July 2013; revised 1 August 2013; accepted 9 August 2013 \\ Copyright (C) 2013 Richard H. Schwartz. This is an open access article distributed under the Creative Commons Attribution License, \\ which permits unrestricted use, distribution, and reproduction in any medium, provided the original work is properly cited.
}

\begin{abstract}
In the past 15 years, there have been more than 40 articles in the medical literature about excessive participation in on-line internet action games by adolescents and young adults. The following case reports provide detailed information on two boys, ages 16 and 20 years respectively, who are compulsive and enthusiastic internet gamers, to the exclusion of family communication, school activities, academic performance, participation in sports and dating. They have not mastered any of the usual goals of adolescent development.
\end{abstract}

Keywords: Internet Game Addiction; Excessive Internet Gaming

\section{INTRODUCTION}

In the past 15 years, there have been more than 40 articles in the medical literature about excessive participation in on-line internet action games by adolescents and young adults [1,2] (Young KS, 1996; Young KS, 1996). The terminology to describe such overuse has been inconsistent, ranging from the term internet game addiction, compulsive internet game use, internet game dependency, and video game disorder. An estimated 1\% - 10\% of two large surveys of German adolescents and young adults fulfilled the criteria for internet addiction in that country [3,4] (Rehbein F, 2013; Beutel ME, 2011). According to the American Psychiatric Association, there is insufficient evidence for such an "addiction" and as such; there is no plan to include internet addiction in the Diagnostic and Statistical Manual V, published in May 2013 [5] (American Psychiatric Association, 2013). However, the term "internet use disorder" was recommended for further study by an expert committee. The DSM-V added a new category of "behavioral addictions" for gambling addictions. Perhaps in future revisions, internet game addiction will be included in this category.

Widely popular action games played on personal computers such as Space Invaders, Pac-Man, Donkey Kong, and Mario Brothers were introduced in the early 1980s. The next generation of action games was developed for game consoles, such as X-box 360, Nintendo, Game Box, and Wii. On-line internet gaming was introduced into North America about six years ago and it has rapidly and widely-increased in participation by adolescents and young adults. The average current Massively Multiplayer Online Role-Playing Game (MMORPG) such as Star Craft, League of Legends, World of Warcraft, Warcrack, LaTale, Maple Story, and Dragon Nest lasts for 30 - 40-minutes of play time, but some can last for more than one hour. Real-world games require payment in the currency of the country to play. Some of the games are without initial cost but add-on payments are often required for additional access to that game or for added game content. Membership to some of the more popular MMORPG games requires a monthly payment which grants monthly access to participate in that selected game. These games are extremely popular with adolescents and young adult males in Japan, Hong Kong, Chinese Taipei, China, and South Korea [6,7]. They combine Hercules-like conquests and overcoming adversity with thrilling graphics, achievement of superiority and admiration from other participants, avoidance of responsibilities and boring homework, and forestalling of the normal adolescent goals. Instead of action games with simple graphics, the recent generation of on-line action games has enhanced large-size color graphics. There are two general types of MMORPG internet action games: Player versus Environment games (PvE) and Player versus Player games $(\mathrm{PvP})$. On-line role playing video games amuse and fascinate large numbers of players who interact with each 
other in the form of alien animated warriors, or creatures with fish or lizard-like faces and bodies. The games pit one small group of players against a competing group of players who reserve a team membership on-line.

The latest internet games, such as Dragon Nest, are very complex and feature 3D action, action heroes, and villains with other-worldly face, body shape, fanciful weapons and self-protection armor. There are special offensive weapons designed to disable or kill with violence, selected enemies. The new generation of games use "currency" earned by completing assigned tasks or by exchange of real money, in order to purchase armor or special weapons which enhance ones effectiveness in the game. One type of currency is earned by killing monsters or the completion of projects or winning territory. Another method to obtain currency requires credit card purchase of protective or ornamental "clothing" for warriors through OG Planet from their on-line fashion shop. Some games have league divisions similar to semi-professional baseball teams. Whereas early generations of internet games required continuous vigilance and performance, some modern day on-line internet video action games are open-ended and they permit players to resume their place in the game after a short break to grab a snack or use the toilet. The following case reports provide detailed information on two boys, ages 16 and 20 years respectively, who are compulsive and enthusiastic internet gamers, to the exclusion of family communication, school activities, academic performance, participation in sports and dating. They have not mastered any of the usual goals of adolescent development.

\section{CASE \#1}

A 16-year-old boy became interested in active participation in on-line action video games during the $8^{\text {th }}$ grade of middle school. In the $6^{\text {th }}$ and $7^{\text {th }}$ grade he was earning A and $\mathrm{B}$ grades in his major subjects. This year he expects to get two $\mathrm{C}$ grades and $2 \mathrm{D}$ grades mostly based on his passing examination grades after a few days of "cramming for the examination”. Based on parent and teacher answers on the Vanderbilt ADHD questionnaire, Case \#1 fulfills criteria for Attention Disorder-Hyperactivity Disorder (inattentive subtype). However, neither his teachers nor his mother noticed any improvement during a trial of stimulant medication. His favorite games include League of Legends and Star Craft. On an average weekday afternoon and evening he spends about six hours per day, from 2:10 PM to 6:30 PM and a few more hours on-line after dinner and quickly-done homework. On Friday, he plays his internet games continuously for 12 hours from 2:30 PM to 3 AM, sleeps five hours from 3 AM to 8 $\mathrm{AM}$, and resumes play again from $8 \mathrm{AM}$ until 3 AM the next morning for a total virtually uninterrupted play for 19 hours. Sunday mornings he resumes internet game play at 8 AM until 9 PM (13-hours). For an estimated 32 of 52 weekends over a one year period, he is glued to his computer playing internet action games. During these internet game marathons, he eats quickly and drinks an average of five large cola beverages during internet games to stay hydrated. At most, he states he is AFK (Away from Keyboard) for about 5 minutes every few games. When at school or shopping, he often thinks about aspects of these internet games and when put on restriction from internet use by his parents or by causing an infraction of the game rules such as failure to complete an action game he cannot stop thinking about his favorite internet action game. During the past 12 months, his on-line purchase of items related to improvement in game performance added up to approximately $\$ 1000$. One estimate calculates world-wide revenues from MMORPG games exceeded one billion dollars in 2008. That money is earned by doing various chores at home. On-line internet game participation also leads to an estimated 6 or 7 arguments per month (more than 1.5 per week) with his parents over his school work performance or the amount of time he spends engrossed in internet gaming, isolated from the rest of the world. There were no prior mental health problems prior to his excessive participation in MMORPG internet action games. He consistently denies use of tobacco products or drinking beer, wine, or distilled spirits. He denies any other drug use. He does not date and has very little motivation for anything other than participation in internet action games.

\section{CASE \#2}

This 20-year-old male has been a regular participant in internet action games for five consecutive years. On weekdays, he starts to play interactive computer games at 9:00 AM and plays almost continuously until midnight. On Saturday, he awakens at 1:00 PM and plays almost continuously until 5:00 AM Sunday morning. Similar to case \#1 above, concomitant with his almost compulsive participation in interactive video games such as La Tale, his school grades suffered a precipitous decline from 3.8 GPA in the first few years of high school to a failing grade point average in 2012: $(1 \mathrm{~F}, 2 \mathrm{Ds}, 1 \mathrm{C}+$, and $2 \mathrm{~B}+$ grades), and as such, he was not permitted to continue as a student at his community college. According to his mother, one teacher commented that he often falls asleep in class, he often appears fatigued in the morning since one or more years ago, and complains of early morning headaches. He currently takes only one course for college credit, is working at his current job for two months earning $\$ 8.00 /$ hour, and spends almost all of his time in his room paying internet MMORPG games. He states: "the real me is when I am playing computer games". In the past, there were no significant problems with anxiety, 
depression, obsessive-compulsive behaviors, or oppositional-defiant symptoms. Case \#2 denies problems with sleep, nutrition, inattention at school, peer relationships, participation in team sport, hobbies, job retention, depression, or loss of self-esteem. For most of these items, his mother has a very different answer. His aspiration is to become a corporate-sponsored "gamer" traveling to foreign countries competing in internet action games wearing his corporate logo shirt.

\section{DISCUSSION}

Compulsive overuse, internet game addiction, impulse control disorder, or internet gaming disorder have all been used as a descriptor for this condition, which, lacking of a diagnostic code in the DSM-V Manual, renders it as a non-diagnostic entity. During adolescence and the early $20 \mathrm{~s}$, extreme participation in modern multiplayer internet action games can be associated with serious consequences that intrude in, stunt, or deviate from adolescent goal-related normative development: school attendance, academic performance, healthy social interaction, initiative and creativity, family responsibilities, and social and family communication [8-13] (Festl R, 2013; Batthyany D, 2009; Ferguson C, 2010; Lam LT, 2009; Young KS, 1999; Kandell JJ, 1998). These are replaced by social isolation, academic underachievement or failure, avoidance of duties of responsibility, sleep disorder, nutritional deficits, and blunting of the normal goals of adolescence which include dating, academic competence, taking responsibilities seriously, vocational aspiration, and independence from parents. In extreme cases of internet game overuse, such as exemplified by the two cases in this report, the major focus in life is on achievements in game performance and the admiration of similar-minded peers, rather than the expected goals of middle and late adolescence.

\section{REFERENCES}

[1] Young, K.S. (1996) Internet addiction: The emergence of a new clinical disorder. The 104th Annual Meeting of the American Psychological Association, 11 August 1996, Toronto.
[2] Young, K.S. (1996) Internet addiction: The emergence of a new clinical disorder. Cyberpsychology, Behavior, and Social Networking, 1, 237-244.

[3] Rehbein, F., Mossle, T., Arnaud, N. and Rumph, H.J. (2013) Video game and internet addiction: The current state of research. Nervenarzt, 84, 569-575.

[4] Beutel, M.E., Hock, C., Wofling, K. and Muller, K.W. (2011) Clinical characteristics of computer game and internet addiction in persons seeking treatment in an outpatient clinic for computer game addiction. Z Zeitschrift fur Psychosomatische Medizin und Psychotherapie, 57, 77-90.

[5] American Psychiatric Association (2013) Diagnostic and statistical manual of mental disorders. 5th Edition, American Psychiatric Publishing, Arlington, 5-25.

[6] Choi, K., Son, H., Park, M., Han, J., et al. (2009) Internet overuse and excessive daytime sleepiness in adolescents. Psychiatry and Clinical Neurosciences, 63, 455-462. doi:10.1111/j.1440-1819.2009.01925.X

[7] Park, H.S., Kwon, Y.H. and Park, K.M. (2007) Factors on internet game addiction among adolescents. Journal of Korean Academy of Nursing, 37, 754-761.

[8] Festl, R., Sharkow, M. and Quandt, T. (2013) Problematic computer game use among adolescents and younger and older adults. Addiction, 108, 592-599. doi:10.1111/add.12016

[9] Batthyany, D., Muller, K.W., Benker, F. and Wolfling, K. (2009) Computer game playing: Clinical characteristics of dependence and abuse among adolescents. Wiener Klinische Wochenschrift, 121, 15-16.

[10] Ferguson, C. (2010) The influence of television and video game use on attention and school problems: A multivariate analysis with other risk factors controlled. Journal of Psychiatric Research, 45, 808-813. doi:10.1016/j.jpsychires.2010.11.010

[11] Lam, L.T., Perry, Z.W., Mai, J.C. and Jing, J. (2009) Factors associated with internet addiction among adolescents. Cyberpsychology, Behavior, and Social Networking, 12, 551-555. doi:10.1089/cpb.2009.0036

[12] Young, K.S. (1999) Internet addiction: Symptoms, evaluation and treatment. Innovations in Clinical Practice, 17, 19-31.

[13] Kandell, J.J. (1998) Internet addiction on campus: The vulnerability of college students. Cyberpsychology and Behavior, 1, 11-17. doi:10.1089/cpb.1998.1.11 